\title{
Efficacy of Mixed Attachment Intervention on Postpartum Depression of Women in Isfahan
}

\author{
Mohammad Hossein Bahadori ${ }^{1}$; Marziyeh Jahanbakhsh ${ }^{1, *}$; Salar Faramarzi ${ }^{1}$; Mohammad \\ Bagher Kajbaf ${ }^{1}$ \\ ${ }^{1}$ Department of Psychology, University of Isfahan, Isfahan, IR Iran \\ *Corresponding author: Marziyeh Jahanbakhsh, Department of Psychology, University of Isfahan, Isfahan, IR Iran. E-mail: m_jahanbakhsh63@yahoo.com
}

Received: August 20, 2013; Accepted: November 19, 2013

\begin{abstract}
Background: Most of women experience postpartum short or long term mood disorders and secure attachment between couple and being supported from husband has important role in improvement of this disorders.

Objectives: Recent research aimed to investigate efficacy of mixed attachment intervention on postpartum depression in women of Isfahan.

Patients and Methods: This study was an experimental plan with pretest- posttest and follow up with control group that conducted in a depended hospital of Isfahan University of medical sciences. Though 325 women that had natural delivery, 38 individuals were chosen who had no history of physical or mental disorder in pregnancy or before that and had taken higher scores in Edinburg depression questionnaire. Selected sample administered randomly to both 19 individuals experimental and control group. Mixed attachment intervention had been accomplished for experimental group as though control group had no intervention. ANCOVA method had been used to analysis the data.

Results: Results of ANCOVA showed that the mean post-test and follow up scores of depression in the experimental group is significantly lower than that of the control group $(\mathrm{P}<0.05)$. The effect rate of mixed attachment intervention on depression symptoms was 0.38 in posttest and 0.41 in three months follow up.

Conclusions: With regard to function of couple`s affective relationship and importance of mother-child attachment, mixed attachment intervention was effective in reduction of postpartum depression symptoms and has important mentions in paying attention to attachment based therapies for decreasing the symptoms of postpartum depression.
\end{abstract}

Keywords: Postpartum; Depression; Mood Disorders

\section{Background}

Post-delivery depression is one of the most common mental disorders after delivery which causes serious problems for the mother, baby and family. Studies report the frequency of this disorder between 5 to 40 percent [1]. Post-delivery depression is a basic depression and necessitates the simultaneous existence of 5 items disturbing physiological order of the body at least one of which is a depressed temper or losing interest in activities [2]. The exact cause of the disorder is still unknown but bases on different studies in addition to biological factors, the most common factors contributing to this disorder include the age of the mother, unwanted (unplanned) pregnancy, unstable job and income situation, family problems and recent life crises [3, 4]. Benig supported by family, having other children and breast feeding are the factors which play an important role in preventing post-delivery depression [5]. Depressed mothers feel less responsible to the newborn baby and face complicated problems in their interaction with the baby [6, 7], which seriously threats emotional- cognitive growth of the baby and may lead to ignorance or malbehavior in childcare $[8,9]$. Concerning the negative effects of depression for the mother and its destructive consequences on the baby and the quality of family life it's extremely important to diagnose the disease in the first weeks after delivery and start early treatment [10]. Medicine is prescribed for those depressed mothers who have previously experienced depression in their life while for those with no experience of psychological disorders before pregnancy it's better to use couple-therapy and supportive treatment $[11,12]$. The findings of new research studies show that for the treatment of post-delivery depression, the role of spouse is more important than any other disorders and husband should actively participate in treatment [13]. Studies show for the treatment of post-delivery depression a good treatment is one that can simplify motherchild as well as wife-husband relationship [14]. The combination of couple-therapy and attachment-based has also been effective in reducing wife-husband complications and increasing intimacy of the partners [15]. Since

Copyright (c) 2015, Zahedan University of Medical Sciences. This is an open-access article distributed under the terms of the Creative Commons Attribution-NonCommercial 4.0 International License (http://creativecommons.org/licenses/by-nc/4.0/) which permits copy and redistribute the material just in noncommercial usages, provided the original work is properly cited. 
mother-child interaction is extremely important in the first months of the life of the baby when mother-child attachment should form and due to the fact that depression in mother can have negative effects on the health of the baby and generally on the foundation of family, the researcher has focused on the ways of improving the disorder of post-delivery depression as the aim of the research. On the other hand since medical treatment is considered the last resort and emotional support by husband and highlighting mother-child touch have been proven effective in treating this disorder, the researcher has aimed at studying and investigating the curing effect of combined attachment interference on post-delivery depression.

\section{Objectives}

Therefore, the research question is whether combined attachment interference is effective in treating post-delivery depression?

\section{Patients and Methods}

The present study was an experimental one consisting of a pre-test, post-test and follows up with a control group which was done in one of the hospitals affiliated with medical university of Isfahan. From 325 women with natural delivery in Shahid Beheshti hospital in Isfahan in 1389, 38 individuals without any history of mental or psychological problems before or during pregnancy who scored the highest in Edinburg depression questionnaire were selected as the target sample. Obtaining a score higher than 13 in Edinburg questionnaire, not having a history of serious mood disorders before pregnancy, not being under any medical treatment simultaneously and having an educational degree of at least diploma were necessary criteria for being included in the study, while obtaining a score lower than 13 , having a history of serious mood disorders before pregnancy, psychosis, characterdisorders type 2, being under medical treatment simultaneously, having an educational degree below diploma, serious family problems and separation or divorce were the criteria for being excluded from the research. The samples were randomly put into two 19-member groups: one experimental and one control group. Considering the fact that test-power higher than 0.8 is considered zero for rejecting hypothesis and this was 0.99 for this research, it can be claimed that sample size was acceptable. The participants in the experimental group took part in 8 sessions of interference through combined attachment (4 sessions individually and 4 sessions with their husbands). The effect of the interference was evaluated by a post-test and after 3 months by follow-up. It's worth mentioning that the participants were instructed to keep their life conditions fixed during the treatment, so that the only factor that affects the women's mood disorders is treatment variables and interfering variables are avoided as much as possible. For moral considerations, the participants participated in the research anonymously and through codes. They were also allowed to stop taking part in treatment at any point throughout the course. The people in the control group were also given 5 sessions of combined attachment therapy after all the stages of the research finished. To be objective, the research was conducted in double-blind way. So the couples did not exactly know what aspect of their mental health and which emotional problem is being investigated. Throughout the treatment, a couple quit attending the sessions due to personal problems so a member of the control group was also randomly removed from statistical analyses. The fact that few number of participants gave up attending the sessions can be attributed to reasons such as the level of education of the couples, their interest in reducing the emotional problems of the wives, and not charging the participants for any fees. Data analyses were also done by a statistics expert who was unaware of the procedure of the research using SPSS 18 software. Data analyses were done through interpretive statistics (Mean and standard deviation) and covariance analysis. In this research Edinburg depression questionnaire was used to find women suffering from post-delivery depression. The questionnaire consists of 10 questions and was prepared by another study. It has been used several times for conducting research on the principles of depression diagnosis and the sensitivity and predictive value of it have been approved in Iran [16]. According to this questionnaire those who score lower than 13 are considered non-depressed and those who score 13 or higher are considered depressed and are referred to experts for necessary treatment. Validity and reliability of the test (through Cronbach Alpha) is reported 0.89 and $81 \%$ respectively out of the country [17]. In addition, in a study by Montazeri et al. the reliability of the questionnaire through Cronbach Alpha was calculated $77 \%$ and through re-test 0.8 in Iran [16]. The trait of the test is $95.7 \%$ and its sensitivity $100 \%$ [18]. For content validity of the treatment sessions, some experts of family consultancy were consulted and the final form was approved by them. The treatment sessions were held in a psychological-consultancy center in Isfahan and the treatment was carried out by a clinical psychologist with 14 years of experience in psychotherapy. During the course, guide books and instructive films through video projector and screen were also used for better clarity of the information. At the end of the course the level of the satisfaction of the individuals, the content of the sessions, guidelines and the effectiveness of the treatment were all assessed by 6 -degree scale. The scores ranged between $4-6$. The activity in each treatment session is summarized below. The first stage: group- sessions with the presence of women.

First session: Familiarity with post- delivery depression and its causes, explaining the importance of treatment for the health of mother and child, exchanges ideas about the birth of baby and how it changes life conditions, giving assignment (Searching signs of depression and its causes in themselves). 
Bahadori MH et al.

Second session: Reviewing the assignment of the previous session, defining parent-child attachment and its examples, critical period of attachment, psychological and physiological needs of baby and the necessity of satisfying the needs, teaching the technique of mother- availability, giving assignment (practicing the technique of availability and satisfying baby's needs on time).

Third session: Reviewing the assignment of the previous session, teaching the technique of touch (physical touch and especially eye- contact) with the baby, scenario- making about how to express real love to baby, and hug, fondle and kiss him, giving assignment (applying the technique of physical touch and eye- contact with the baby).

Fourth session: Reviewing the assignment of the previous session, explaining the importance of being happy and caring about oneself and one's husband, stress management in family, the necessity of patience and tolerance to pass the critical first year after delivery, giving assignment (planning at least 2 fun activities a weak, privacy with husband and talking about needs and expectations). The second stage: group- session with the presence of both partners.

Fifth session: stating the principles and purposes of the group, explaining the importance of complete cooperation of both parents in child- care and the role of lack of getting support from husband in post- delivery depression, strategies for sharing responsibilities, emotional support by husband, giving assignment (sharing responsibilities in a new way, taking note of expectations from each other).

Sixth session: reviewing the assignment of the previous session, defining attachment, clarifying the difference between attachment and dependence, explaining how attachment- style forms, recognition of attachment style based on the attitude of people to themselves and others, explaining the change in attachment style, giving assignment (recognition and taking notes of right and wrong patterns of inter- personal attachment).

Seventh session: reviewing the assignment of the previous session, clarifying the difference between attachment in children and adults, investigating the relationship between changing attachment style and romantic love, investigating sexual behavior before and after the birth of the baby, clarifying the role of attachment in sexual relationship, giving assignment (Repairing the impaired pattern of sexual relationship, practicing secure attachment relationship). Eighth session: Reviewing the assignment of the previous session, a brief investigation of sexual information of the couple, instructing the couples about how to express their sexual excitement, summarizing the information offered during the previous sessions, investigating the assignment and trouble-shooting, final summarization of the information and concluding, applying post- test and finishing the treatment sessions.

\section{Results}

The participants of the research were women refer- ring to Shahid Beheshti Hospital of Isfahan University of Medical Sciences who had had natural delivery 6 to 12 months earlier and whose age average and standard deviation was $(27.23 \pm 8.84$ years $)$ in the control group, in addition, other demographic traits of the members of the experimental and control group such as socialeconomical status (24.1\% low average, 64.33\% average, $\% 8.55$ rather wealthy) and educational level of husband (diploma 72.5\%, A.A 10\%, B. S/B. A 14.5\%, M. S/M. A 3\%) were evaluated and compared through descriptive statistical indices (Frequency and distribution). However the investigation of the results of independent t-test showed there is no significant difference between the experimental and control group regarding the above- mentioned demographic traits $(\mathrm{P}>0.05)$. Therefore, due to lack of correlation between the demographic traits and the dependent variable, there was no need to statistically control them. Table 1 indicates descriptive indices of the central tendency of dependence variable- total symptoms of post- delivery depression categorized in groups and stages. Mean and standard deviation of the symptoms of post- delivery depression in the control group in pre- test stage are respectively 17.62 and 5.89 while those of the experimental group are 17.02 and 6.12 respectively. In posttest stage, the mean of symptoms in the control group was 16.24 and the standard of deviation equaled 4.27. But in the experimental group the mean decreased to 10.25 and the standard deviation to 2.48. Finally after 3 months the follow- up stage war done which showed the mean and standard of deviation of the symptoms of post- delivery depression in the control group equaled 16.10 and 4.41 respectively and in the experimental group these figures were 9.63 respectively. Since covariance analysis is an example of parametric tests, the presumption of the normality of distribution and equality of variances was investigated. Shapiro-wilk test was applied to investigate the presumption of normality. The results show that in the control group Shapiro-wilk figure was 0.86 $\mathrm{P}=0.12$ while in the experimental group it was $0.95 \mathrm{P}=$ 0.72 which indicate that the scores in the two groups are normally distributed. In addition, levin test was done to investigate the equality of variances. The results revealed that in post- test stage levin figure is $1.05 \mathrm{P}=0.31$ and in follow- up it is $1.20 \mathrm{P}=0.28$ which proves that the distribution of scores of pre-test is the same in both control and experimental groups. Therefore the presumption of the equality of variances is supported and since score distribution is normal, covariance analysis can be used. Table 2 shows the results of covariance analysis to compare the two groups concerning the post- test and follow- up after controlling the pre- test. As it is seen there is a significant difference between the scores of pre-test and post- test (P $\leq 0.001)$. Due to the fact that only pre- test is related to the total scores of post- delivery depression in the stages of post-test and follow-up, pre-test is considered an interfering variable and should be controlled. In other words, that part of the variance of the total scores of post-deliv- 
ery depression which is related to pre- test is subtracted from the total variance of the scores. Therefore, pre-test is included in covariance analysis as a variable to remove the effect of that in group- membership variance. However, even after controlling the effect of pre-test, there is still significant difference between the two groups in post-test and follow up scores of post-delivery depression with a degree of freedom of $95 \%$ and the size of the effect of combined attachment interference on the symptoms of depression in pretest equals 0.38 and in 3- month follow- up stage equals 0.41 .

Table 1. Comparing of Mean and Standard Deviation of PostDelivery Depression Symptoms Total Scores

\begin{tabular}{lc}
\hline Process & Mean \pm SD \\
\hline Control & \\
\hline Pretest & $17.62 \pm 5.89$ \\
\hline Posttest & $16.24 \pm 4.27$ \\
\hline Follow up & $16.10 \pm 4.41$ \\
\hline Experimental & \\
\hline Pretest & $17.02 \pm 6.12$ \\
\hline Posttest & $10.25 \pm 2.48$ \\
\hline Follow up & $9.63 \pm 2.09$ \\
\hline
\end{tabular}

Table 2. Results of Covariance Analysis of Group Membership Effect on Post-Delivery Depression in Two Groups

\begin{tabular}{ll}
\hline Research Variables & P Value \\
\hline Post-Delivery Depression & \\
Post test & \\
Pretest & 0.001 \\
Group membership & 0.001 \\
Follow up & \\
Pretest & 0.001 \\
Group membership & 0.001 \\
\hline
\end{tabular}

\section{Discussion}

The present study was conducted with the aim of investigating the effect of combined attachment interference on post-delivery depression in Isfahan. The results of covariance analysis showed the symptoms of post-delivery depression disorder in the participating women in the experimental group significantly decreased in post-test and follow-up stages compared to the control group. The finding indicated that combined attachment can be very helpful in treating minor post- delivery depression. Therefore, it can be concluded that medicine is not- always the first option for treating post- delivery depression and a combination of supportive couple therapy and using mother- child as well as couple attachment can be a very good solution for this problem. Moreover, the fact that the treatment continued to make progress in post-test proves that repairing the pattern of relationship between couples cause the symptoms of post- delivery depression to decrease continuously and can consequently improve mental health of the family. Plus, secure mother- child attachment helps mental and physical health of both mother and child and prevents any possible mood disorders for them. In line with the finding of this research in another study it was made clear that attachment-based therapy is effective in post- delivery depression disorder, as mood disorders and emotional problems of mother decreased when mother- child attachment increased [13]. Also, this study supports the findings of Johnson's research [19] which claim motherchild skin-touch is helpful in improving post-delivery depression disorder. In addition, this research supported the previous studies in that psychotherapy without using drugs can also improve the symptoms of post-delivery depression [12]. The researcher used interference in the form of attachment therapy combined with couple therapy based on attachment because of 2 reasons: firstly it was because of the presumption that lack of receiving sufficient support from the side of husband and weak interactions between couples can be regarded as one of the main causes of post- delivery depression. As Tannous et al. [2] believes weak quality of wife- husband interaction and lack of receiving sufficient support from husband is one of the most important risk factors in this disorder and many research studies support this idea. It has also been proven that women who have problems in their relationship with their husbands are at a higher stake of post- delivery depression [20]. Secondly, it's proven that making intimate relationship and forming parent- child attachment link on time has a basic role in mental health of both mother and child. In addition those mothers who benefited from social support such as having a friend, good relationship with her family as well as in- low family and being supported by husband after delivery feel more confident about their role as a mother and have more satisfaction with motherhood [4]. The research by Bjerke et al. [21] also indicates there is a significant relationship between post-delivery depression and not receiving social support which is in line with the findings of previous research. In the present research, the participants were instructed about having correct insight into the signs of depression in mothers, the negative consequences of depression on the mental and physical health of mother and child, the effect of stress on mother and embryo, the role of mother- child attachment, the effect of being supported by husband and having intimate relationship on treatment and the role of happiness in strengthening family relationship. Necessary suggestions were also given to mothers about their mental and physical health for self- care. These items not only made the mothers aware of the signs of depression, but also increased their hope in recovery. Every research has some limitation and the present research is not an exception. Considering the fact that depression disorder is basic, a 3 month follow-up pe- 
riod does not seem sufficient for a complete investigation of the procedure of recovery and improvement. It's suggested that in the following research studies, longer period be used. Moreover since in this study group therapy was used it's suggested that the same treatment be done on the participants individually and then the results be compared. Since the study was done on a sample of depressed women in Isfahan, generalization of the results to other research is not paying attention to the first, second or next deliveries of the participants, so it can be taken in to account in further research. Further research can investigate the effect of combine attachment-therapy on other mental disorders with a bigger population to help the treatment of mood disorders of women. The research was approved by scientific committee of Isfahan University and the topic was not related to personal interests of the researchers. We appreciate all the people who helped us in conducting the research including the participants.

\section{Acknowledgements}

Thanks to all those who we hold in our study and also helped the participants in the study. This article is the result of a MA Dissertation in Psychology course with the title as "The efficacy of attachment based therapy on behavioral problem in girls with attachment problems" that operated in supervision of Isfahan University's scientific committee.

\section{Authors' Contributions}

All authors had equal role in design, work, statistical analysis and manuscript writing.

\section{Funding/Support}

University of Isfahan.

\section{References}

1. Iles J, Slade P, Spiby H. Posttraumatic stress symptoms and postpartum depression in couples after childbirth: the role of partner support and attachment. J Anxiety Disord. 2011;25(4):520-30.

2. Tannous L, Gigante LP, Fuchs SC, Busnello ED. Postnatal depression in Southern Brazil: prevalence and its demographic and socioeconomic determinants. BMC Psychiatry. 2008;8:1.

3. Kendall-Tackett K. A new paradigm for depression in new mothers: the central role of inflammation and how breastfeeding and anti-inflammatory treatments protect maternal mental health. Int Breastfeed J. 2007;2:6.

4. Wissart J, Parshad O, Kulkarni S. Prevalence of pre- and postpartum depression in Jamaican women. BMC Pregnancy Childbirth. 2005;5:15.

5. Hassert S, Kurpius SER. latinas and postpartum depression: role of partner relationship, additional children, and breastfeeding.J Multicult Couns Devel. 2011;39(2):90-100.

6. Baptist JA, Thompson DE, Norton AM, Hardy NR, Link CD. The effects of the intergenerational transmission of family emotional processes on cnflict styles: the moderating role of attachment. Am J Fam Ther. 2012;40(1):56-73.

7. Posmontier B. Sleep quality in women with and without postpartum depression.J Obstet Gynecol Neonatal Nurs. 2008;37(6):722-35.

8. Vesga-Lopez O, Blanco C, Keyes K, Olfson M, Grant BF, Hasin DS. Psychiatric disorders in pregnant and postpartum women in the United States. Arch Gen Psychiatry. 2008;65(7):805-15.

9. McCoy SI, Beal JM, Shipman SB, Payton ME, Watson GH. Risk factors for postpartum depression: a retrospective investigation at 4-weeks postnatal and a review of the literature. J Am Osteopath Assoc. 2006;106(4):193-8.

10. Meir ST, Kimberly AY, Elias E. Mood disorder in women. Psychiatry Neurosci. 2002;28(2):139-40.

11. Suri R, Altshuler L. postpartum depression: advances in recognition and treatment. Focus. 2012;10(1):15-21.

12. Whisman MA, Davila J, Goodman SH. Relationship adjustment, depression, and anxiety during pregnancy and the postpartum period.J Fam Psychol. 2011;25(3):375-83.

13. Gremigni P, Mariani L, Marracino V, Tranquilli AL, Turi A. Partner support and postpartum depressive symptoms. J Psychosom Obstet Gynaecol. 2011;32(3):135-40.

14. Paris R, Bolton RE, Spielman E. Evaluating a home based dyadic intervention: changes in postpartum depression, maternal perceptions, and mother-infant interactions. Infant Ment Health J. 2011;32(3):319-38.

15. Vogel L. Tailored treatment for postpartum depression. Can Med Assoc J. 2011;183(16):E1163-4.

16. Montazeri A, Torkan B, Omidvari S. The Edinburgh Postnatal Depression Scale (EPDS): translation and validation study of the Iranian version. BMC Psychiatry. 2007;7:11.

17. Eberhard-Gran M, Eskild A, Tambs K, Opjordsmoen S, Samuelsen SO. Review of validation studies of the Edinburgh Postnatal Depression Scale. Acta Psychiatr Scand. 2001;104(4):243-9.

18. Boyce P, Stubbs J, Todd A. The Edinburgh Postnatal Depression Scale: validation for an Australian sample. Aust N Z J Psychiatry. 1993;27(3):472-6.

19. Johnson C. Impact of kangaroo care (skin-to-skin contact) on attachment formation between preterm infants and their caregivers.: Pacific University Oregon; 2010. Available from: http://commons. pacificu.edu/otpeds/9.

20. Nakku JE, Nakasi G, Mirembe F. Postpartum major depression at six weeks in primary health care: Prevalence and associated factors. Afr J Health Sci. 2006;6(4):207-14.

21. Bjerke SE, Vangen S, Nordhagen R, Ytterdahl T, Magnus P, StrayPedersen B. Postpartum depression among Pakistani women in Norway: prevalence and risk factors. J Matern Fetal Neonatal Med. 2008;21(12):889-94. 